\title{
Based on the Multi-attribute Fuzzy Decision- Making of Anti-ship Missile Attacks on the Sea Scheme Optimization
}

\author{
Wang Shu Qi \\ Department of Surface Ship Command, Dalian Naval \\ Academy, Dalian, 116018,China; \\ E-mail: mailbox1314@126.com
}

\author{
Ma Liang \\ Department of Surface Ship Command, Dalian Naval \\ Academy, Dalian, 116018,China; \\ E-mail: maliang2014@tom.com
}

\begin{abstract}
Using the multi-attribute fuzzy decision-making method, the mathematical model of the minimum weighted average deviation method to the fleet to the sea combat missiles combat the effect, the fleet command coordination ability, the missile lead attack ability and the elements such as combat damage index system are analyzed, and concluded with a core of a new type of destroyers fleet optimization scheme, which is of great significance to the improvement of comprehensive fleet combat ability.
\end{abstract}

Keywords-destroyers fleet optimization scheme;the optimal relative; multi-attribute fuzzy decision-making

\section{INTRODUCTION}

In the modern sea battle, both sides in the form of a surface ship are the basic formation of a confrontation. Under the condition of informationization, penetrating can integrate the advantages of single ship form a multifunction, multi-level, all-round, a wide range of offensive and defensive system, create favorable for the formation of single warship combat environment, make each ship to hard and soft weapon maximum efficiency, so as to better play the overall power, form the strong comprehensive capability formation. Thus, surface ship formation is effective to effectively weaken enemy on the sea, to fight for creating conditions, to achieve the purpose of the combat against, on the formation requires good tree, military makes scientific use be well in the combat with all kinds of combat power, to give full play the overall operational effectiveness.

Like penetrating scheme evaluation and selection of military decision making problems, in essence, is a kind of multi-attribute fuzzy decision-making problem, at present the method can effectively solve such problems: fuzzy iterative decision-making method, the fuzzy neural network integrated decision-making method and entropy weight fuzzy decision-making method, etc. Here, a new method of minimum weighted average deviation is introduced and it is in a new type of destroyers, the core of tf plan is optimized as a preliminary study on the application.

\section{A DESCRIPTION OF THE PROBLEM AND ITS MATHEMATICAL MODEL}

Military commanders in the plan optimization, the controllers (or decision makers) usually consider various fuzzy factors, formulate $\mathrm{n}$ a preliminary plan $B_{1}$, $B_{2}, \ldots, B_{n}$, and need to evaluate this $\mathrm{n}$ plan to determine the optimal solution. $\mathrm{N}$ solutions are consist of a set as $\mathrm{B}=\left\{B_{1}, B_{2}, \ldots, B_{n}\right\}$. Decision makers consider all the factors as set $\mathrm{F}=\left\{F_{1}, F_{2}, \ldots, F_{m}\right\}$. Set $y_{i j}$ is the first i plan factor characteristic value $B_{j}$, characteristic matrix as factors $Y=\left(y_{i j}\right)_{m \times n}$. Factor considers generally, there are four types: the bigger the optimal type, the smaller type, fixed and interval, which can be divided into $F^{k}(\mathrm{k}=1,2,3,4)$, and:

$$
\begin{aligned}
& F=\bigcup_{k-1}^{4} F^{k}, \quad F^{k} \cap F^{l}=\varnothing, \quad k \neq l \\
& F^{k}(k=1,2,3,4) \text { are respectively efficiency, cost, }
\end{aligned}
$$
fixed type and interval goal set, for the empty set. To increase the comparability and eliminate the influence of different physical quantities on the scheme evaluation results, the general requirements for normalization, first membership degree formula combined with Chad, choose the normalization formula, which is as follows:

The efficiency goals for its optimal relative formula

$$
r_{i j}=\frac{\left(y_{i j}-\min y_{i j}\right)}{\left(\max y_{i j}-\min y_{i j}\right)} \mathrm{j}=1,2, \cdots, \mathrm{n} ; \mathrm{i} \in F^{1}
$$

Type the cost target for the optimal relative formula

$$
r_{i j}=\frac{\left(\max y_{i j}-y_{i j}\right)}{\left(\max y_{i j}-\min y_{i j}\right)}, 1,2, \cdots, \mathrm{n} ; \mathrm{i} \in F^{2}
$$

Type of fixed target for its optimal relative formula

$$
r_{i j}=\left\{\begin{array}{l}
1, \quad y_{i j}=y_{i}^{*} \\
1-\frac{\left|y_{i j}-y_{i}^{*}\right|}{\delta_{i}}, y_{i j} \neq y_{i}^{*}, j=1,2, \cdots, n ; i \in F^{3}
\end{array}\right.
$$
formula

Type of interval target for its optimal relative

$$
\begin{aligned}
& r_{i j}=\left\{\begin{array}{l}
1-\frac{d_{i}-y_{i j}}{\beta_{i}}, y_{i j}<d_{i} \\
1, y_{i j} \in\left[d_{i}, d^{i}\right], \quad j=1,2, \cdots, n ; i \in F^{4} \\
1-\frac{y_{i j}-d^{i}}{\beta_{i}}, y_{i j}>d_{i}
\end{array}\right. \\
& \delta_{i}=\max _{1 \leq j \leq n}\left|y_{i j}-y_{i}^{*}\right|, \quad i \in F^{3}
\end{aligned}
$$




$$
\beta_{i}=\max \left\{d_{i}-\min y_{i j}, \max y_{i j}-d_{i}\right\}, i \in F^{4}
$$

Then, according to (1) (2) (3) and (4) type, element characteristic matrix can be transferred to the relative membership degree matrix:

$$
r=\left(r_{i j}\right)_{m \times n}=\left(\begin{array}{ccc}
r_{11} & \cdots & r_{1 n} \\
\vdots & \ddots & \vdots \\
r_{m 1} & \cdots & r_{m n}
\end{array}\right)
$$

In tf scheme selection, the plan is only in the solution set $\mathrm{B}$, and has nothing to do with the outside of plan $\mathrm{B}$, which is the relativity of scheme selection. Therefore, it can be defined relatively ideal solution for:

$$
\begin{gathered}
G=\left(g_{1}, g_{2}, \cdots, g_{m}\right)^{T} \\
g_{i}=\max _{1 \leq j \leq n} r_{i j}, i=1,2, \cdots, m
\end{gathered}
$$

Policymakers knowledge, experience, expectations and decision-making style preference information can be reflected through the attribute weights, a weight vector is:

$$
\begin{gathered}
\omega=\left(\omega_{1}, \omega_{2}, \cdots, \omega_{m}\right)^{T}, \omega_{i} \geq 0 \\
\sum_{i=1}^{m} \omega_{i}=1, i=1,2, \cdots, m
\end{gathered}
$$

Due to the preference, information is difficult to know in advance, therefore, the weight vector is pending an unknown quantity.

Argument Plan G, the closer the relatively ideal is optimal, therefore, the available solution to measure the degree of deviation from $\mathrm{G}$, now select the following indicators:

$$
\theta_{j}(\omega)=\sum_{i=1}^{m} \omega_{i}\left(g_{i}-\mathrm{r}_{i j}\right), j=1,2, \cdots, n
$$

hat for a given weight vector $\omega$, the smaller $\theta_{j}(\omega)$ the corresponding to the optimal. So to establish a multicriteria decision model as follows:

$$
\begin{array}{r}
\min \left\{\theta(\omega)=\theta_{1}(\omega), \theta_{2}(\omega), \cdots, \theta_{n}(\omega)\right\} \\
\text { s.t. } \sum_{i=1}^{m} \omega_{i}^{2}=1, \omega_{i} \geq 0, i=1,2, \cdots, m
\end{array}
$$

Table I

\begin{tabular}{|c|c|}
\hline PlanA & 1 the ships of the new destroyers +4 X Y type frigates \\
\hline PlanB & Ships of the new destroyers +2 X 1 Y frigate +2 Z frigates \\
\hline PlanC & 2 ships of the new destroyers +3 X Y frigates \\
\hline PlanD & 2 ships of the new destroyers +1 X Y frigate +2 Z frigates \\
\hline
\end{tabular}

Target threat judgment is an important part of warship command automation decisions, its main task is to judge the threat degree of the target ship, the auxiliary vessels for battlefield commander reasoning, judgment, decision and command to me by real-time automatic (semi-automatic). In terms of warship air defense combat
Since each scheme is not bad, there is no preference relations, therefore, power a rally for the following single criterion planning problems such as:

$$
\begin{gathered}
\min \left\{\sum_{i=1}^{m} \theta_{j}(\omega)\right\} \\
\text { s.t. } \sum_{i=1}^{m} \omega_{i}^{2}=1, \omega_{i} \geq 0, i=1,2, \cdots, m
\end{gathered}
$$

Solving the weight vector and the standardization of available:

$$
\omega_{i}^{*}=\frac{\sum_{j=1}^{n}\left(g_{i}-r_{i j}\right)}{\sum_{j=1}^{n} \sum_{i=1}^{m}\left(g_{i}-r_{i j}\right)}, i=1,2, \cdots, m
$$

The weight vector $\omega^{*}=\left(\omega_{1}^{*}, \omega_{2}^{*}, \cdots, \omega_{m}^{*}\right)^{T}$ put in (5), then $\theta_{j 0}\left(\omega^{*}\right) \quad, \quad j=1,2, \cdots, n \quad$, $\theta_{j 0}\left(\omega^{*}\right)=\min _{1 \leq j \leq n}\left\{\theta_{j 0}\left(\omega^{*}\right)\right\}$

the corresponding solution is the most satisfied with the plan, and follow the rise $\theta_{j 0}\left(\omega^{*}\right)$ which is from small to large sequence can be the demonstration of the optimal solution sequence alignment.

\section{A NEW DESTROYER AS THE CORE OF THE TF PLAN OPTIMIZATION}

With the core of a new type of destroyers to naval fleet, the fleet commanders to comprehensive consideration of many factors, evaluation and optimization a variety of solutions are put forward. Formation scheme can be conducted using the above methods. The commander optimal decision, obtains a variety of solutions of optimal sequence alignment.

According to the author's fleet which may weave scheme according to the task that the author drives naval fleet, waters, and they fight ability and the formation of the basic principles, considering the author's formation may have battle damage, etc., drawing a new destroyer as the core of tf basically has the following several forms. system, to the size of target threat and the target type, distance, relative motion posture, altitude, speed, and many other factors. For outlining the problem, this paper sets up the index of initial data and actual data can be extracted through the appropriate way, which is shown in Table 1. 


\begin{tabular}{|c|c|c|c|c|c|c|c|c|c|}
\hline \multirow{2}{*}{$\begin{array}{l}\text { Threa } \\
t \\
\text { index }\end{array}$} & \multicolumn{6}{|c|}{ target index characteristic values } & \multicolumn{3}{|c|}{ values } \\
\hline & 001 & 002 & 003 & 004 & 005 & 006 & 1 & 2 & 3 \\
\hline $\begin{array}{c}\text { distan } \\
\text { ce }\end{array}$ & 41 & 52 & 35 & 25 & 120 & 150 & $\leq 30$ & $\begin{array}{c}30 \\
- \\
60\end{array}$ & $\geq 60$ \\
\hline $\begin{array}{l}\text { Relati } \\
\text { ve } \\
\text { motio } \\
n \\
\text { Angle }\end{array}$ & 0.5 & 0 & 10.5 & 0.8 & 50.5 & 80 & $\leq 30$ & $\begin{array}{c}30 \\
- \\
70\end{array}$ & $\geq 70$ \\
\hline height & 50 & 110 & $\begin{array}{c}150 \\
0\end{array}$ & 50 & $\begin{array}{c}200 \\
0\end{array}$ & $\begin{array}{c}300 \\
0\end{array}$ & $\begin{array}{c}\leq 10 \\
0\end{array}$ & $\begin{array}{l}10 \\
0- \\
10 \\
00\end{array}$ & $\begin{array}{c}\geq 100 \\
0\end{array}$ \\
\hline speed & 250 & 150 & 220 & 410 & 150 & 210 & $\begin{array}{c}\geq 30 \\
0\end{array}$ & $\begin{array}{c}20 \\
0- \\
30 \\
0\end{array}$ & $\leq 200$ \\
\hline
\end{tabular}

From Table 1, threat index and criteria values matrix eigenvalue matrix can be seen, respectively:

$$
\begin{gathered}
X=\left[\begin{array}{cccccc}
41 & 52 & 35 & 25 & 120 & 150 \\
0.5 & 0 & 10.5 & 0.8 & 50.5 & 80 \\
50 & 110 & 1500 & 50 & 2000 & 3000 \\
250 & 150 & 220 & 410 & 150 & 210
\end{array}\right] \\
Y=\left[\begin{array}{ccc}
30 & 30-60 & 60 \\
30 & 30-70 & 70 \\
100 & 100-1000 & 1000 \\
300 & 200-300 & 200
\end{array}\right]
\end{gathered}
$$

Standard reference index matrix $Y$ and the actual situation of the incoming target, target threat of variable fuzzy sets to attract (mainly) domain matrix and range domain matrix and point $M_{i h}$ matrix, respectively:

$$
\begin{array}{r}
I_{a b}=\left[\begin{array}{lll}
{[0,30]} & {[30,60]} & {[60,200]} \\
{[0,30]} & {[30,70]} & {[70,90]} \\
{[20,100]} & {[100,1000]} & {[1000,5000]} \\
{[500,300]} & {[300,200]} & {[200,100]}
\end{array}\right] \\
I_{c d}=\left[\begin{array}{lll}
{[0,60]} & {[0,200]} & {[30,200]} \\
{[0,70]} & {[0,90]} & {[30,90]} \\
{[20,1000]} & {[20,5000]} & {[100,5000]} \\
{[500,200]} & {[500,100]} & {[300,100]}
\end{array}\right] \\
M=\left[\begin{array}{lll}
0 & 30 & 200 \\
0 & 30 & 90 \\
20 & 100 & 5000 \\
500 & 300 & 100
\end{array}\right]
\end{array}
$$

Use type (2) or (3) to calculate difference degree $D_{\tilde{A}}\left(x_{i j}\right)_{h}$, again use type (1) to calculate the relative membership degree $\mu_{\tilde{A}}\left(x_{i j}\right)_{h}$ index of level $h$. Use Matlib7.0 computing tools available

$$
\begin{aligned}
& D_{\tilde{A}}\left(x_{i j}\right)_{1}=\left[\begin{array}{llllll}
0.36 & 0.73 & 0.17 & 0.17 & -1 & -1 \\
0.98 & 1 & 0.95 & 0.97 & 0.51 & -1 \\
0.63 & -1 & -1 & 0.63 & -1 & -1 \\
0.5 & -1 & 0.8 & 0.55 & -1 & 0.8
\end{array}\right] \\
& U_{1}=\left[\begin{array}{llllll}
0.68 & 0.865 & 0.585 & 0.585 & 0 & 0 \\
0.99 & 1 & 0.975 & 0.985 & 0.755 & 0 \\
0.815 & 0 & 0 & 0.815 & 0 & 0 \\
0.75 & 0 & 0.9 & 0.775 & 0 & 0.9
\end{array}\right] \\
& D_{\tilde{A}}\left(x_{i j}\right)_{2}=\left[\begin{array}{llllll}
0.63 & 0.27 & 0.83 & 0.17 & 0.43 & 0.64 \\
0.98 & 1 & 0.65 & 0.97 & 0.49 & 0.5 \\
0.63 & 0.99 & 0.13 & 0.63 & 0.25 & 0.5 \\
0.5 & 0.5 & 0.2 & 0.55 & 0.5 & 0.1
\end{array}\right] \\
& U_{2}=\left[\begin{array}{llllll}
0.815 & 0.635 & 0.915 & 0.585 & 0.715 & 0.82 \\
0.99 & 1 & 0.825 & 0.985 & 0.745 & 0.75 \\
0.815 & 0.995 & 0.565 & 0.815 & 0.625 & 0.75 \\
0.75 & 0.75 & 0.6 & 0.775 & 0.75 & 0.55
\end{array}\right]
\end{aligned}
$$

$$
\begin{array}{r}
D_{\tilde{A}}\left(x_{i j}\right)_{3}=\left[\begin{array}{llllll}
0.63 & 0.27 & 0.83 & 0.17 & 0.43 & 0.64 \\
-1 & -1 & -1 & -1 & 0.49 & 0.5 \\
-1 & 0.99 & 0.13 & 0 & 0.25 & 0.5 \\
0.5 & 0.5 & 0.2 & -1 & 0.5 & 0.1
\end{array}\right] \\
U_{3}=\left[\begin{array}{llllll}
0.815 & 0.635 & 0.915 & 0.585 & 0.715 & 0.82 \\
0 & 0 & 0 & 0 & 0.745 & 0.75 \\
0 & 0.995 & 0.565 & 0.5 & 0.625 & 0.75 \\
0.75 & 0.75 & 0.6 & 0 & 0.75 & 0.55
\end{array}\right]
\end{array}
$$

Based on literature [2, 3] ordered binary comparison and mood operator, sort threat indexes matrix and index weight vector respectively:

$$
F=\left[\begin{array}{cccc}
0.5 & 0 & 0 & 0 \\
0 & 0.5 & 1 & 1 \\
1 & 0 & 0.5 & 0 \\
1 & 0 & 1 & 0.5
\end{array}\right]
$$

$\omega=(0.062,0.554,0.118,0.267)$

The sort of threat indexes is: relative motion posture, speed, height, distance.

Get the distance parameter $p=1$. According to type (4) and (5), the normalized and normalized relative membership degree matrix can be obtained respectively:

$\left[\begin{array}{llllll}0.987 & 0.866 & 0.976 & 0.987 & 0.747 & 0.633\end{array}\right] \quad\left[\begin{array}{lllllll}0.377 & 0.338 & 0.379 & 0.391 & 0.286 & 0.256\end{array}\right.$

$U^{\prime}=\left[\begin{array}{llllll}0.989 & 0.992 & 0.937 & 0.987 & 0.932 & 0.918 \\ 0.64 & 0.978 & 0.660 & 0.54 & 0.932 & 0.98\end{array}\right]\left[\begin{array}{llllll}0.378 & 0.387 & 0.364 & 0.391 & 0.357 & 0.372 \\ 0.245 & 0.276 & 0.57 & 0.218 & 0.357 & 0.372\end{array}\right]$ $\left[\begin{array}{llllll}0.640 & 0.707 & 0.660 & 0.549 & 0.932 & 0.918\end{array}\right] \quad\left[\begin{array}{llllll}0.245 & 0.276 & 0.257 & 0.218 & 0.357 & 0.372\end{array}\right]$

Using type (6) available level eigenvalue vector is $\mathrm{H}=(1.868,1.94,1.878,1.868,1.94,2.116)$.

In $\mathrm{X}$ new destroyer which is the core of the fleet plan optimization, the main factors are to consider the following: 
Missile combat effect $F_{1}$ : the main factors influencing the combat effect of sea battle fleet are carrying the operational capability of anti-ship missile and the number of anti-ship missile, which belong to the bigger optimal type. Generally speaking, the formation of carrying missile number, the more and better the performance of missile and the concept of vessel equipment and charge system is, the better and greater the formation of sea warfare capability index is. In addition, the formation is a target quantity, formation can be a volley of missiles quantity which also affects the combat effect of sea warfare. To combat the effect of the above criteria, more fighting effect of various elements, after the assignment calculation:

$$
F_{1}=\{12.08,12.08,14.72,14.72\}
$$

Command coordination ability $F_{2}$ : force command and coordination ability, formation of ships in formation and type of the total number of ships, attack wave time needed to complete tasks and direct means and so on, belong to the bigger optimal type. In general, the more ships in formation, which is within the total numbers of ships, the more the attack wave time is needed to complete tasks, the more the sophisticated command and synergy is. And what is in command and synergy ability request is as big as possible, therefore, in the calculation, some indexes of command and coordination abilities (such as in ship formation types attack wave number, to complete the task need inferior) are taken inversely in calculation after assignment:

$$
F_{2}=\{1.557,2.104,1.487,2.104\}
$$

Lead attack ability $F_{3}$ : assault possibility is the ability to fleet to attack enemy formation as soon as possible, which belongs to the bigger optimal type. It and the unit are equipped with guided force over-the-horizon radar. Over-the-horizon attack can reach other factors. Among them, the helicopter is one of important guiding force in over-the-horizon attack. Formation is within the range of anti-ship missile gap and the influencing factors of assault possibility. If the missile range difference is too big, some vessels may attack, while some may not, finally leading to the failure of the fleet assault. Through value calculation.:

$$
F_{3}=\{2.14,2.14,2.64,2.64\}
$$

Loss index system $F_{4}$ : the main factors of influence to the loss of combat is fleet anti-missile combat ability, the formation of radar stealth, anti-destroying ability formation and formation of heavy resistance, belong to the smaller type. Generally speaking, the better the formation anti-missile capabilities are, the smaller fleet combat damage is; the better the formation of radar stealth is, the smaller fleet combat damage is; the better the formation anti-destroying ability is, the smaller fleet combat losses are; the better the fleet sink resistance is, the smaller the fleet combat damage is. Through value calculation:

$$
F_{4}=\{1.42,0.91,1.37,1.16\}
$$

Wing commander, according to the mathematical model of multi-attribute fuzzy decision-making method for the above four factors, can get factor characteristic matrix as follows:

$$
Y=\left(\begin{array}{llll}
12.08 & 1.557 & 2.14 & 1.42 \\
12.08 & 2.104 & 2.14 & 0.91 \\
14.72 & 1.487 & 2.64 & 1.37 \\
14.72 & 2.104 & 2.64 & 1.16
\end{array}\right)
$$

Calculate relative membership degree matrix, which is available:

$$
r=\left(\begin{array}{cccc}
0 & 0.113 & 0 & 0 \\
0 & 1 & 0 & 1 \\
1 & 0 & 1 & 0.098 \\
1 & 1 & 1 & 0.510
\end{array}\right)
$$

According to (5), (6), it can be obtained:

$$
\begin{aligned}
& \theta\left(\omega^{*}\right)=\left\{\theta_{1}\left(\omega^{*}\right), \theta_{2}\left(\omega^{*}\right), \theta_{3}\left(\omega^{*}\right), \theta_{4}\left(\omega^{*}\right)\right\} \\
& =\{0.528,0.401,0.428,0.098\}
\end{aligned}
$$

Easy to see, the order of the optimal solution is:

$$
B_{4}>B_{2}>B_{3}>B_{1}
$$

This is in conformity with the artificial judgment practice.

\section{CONCLUSION}

This article expounds a multi-attribute fuzzy decision-making method, and combines with the naval battle with $\mathrm{X}$ new destroyer as the core of the tf plan optimization examples, introduces the application of this method. The results obtained from the calculation is correct, consistent with the actual, this method is also suitable for the study of other military decision making problems, which provides a scientific decision for the command personnel guarantee.

\section{REFERENCES}

[1] WANG Hong-jun, CHI Zhong-xian.Shipboard hard and soft weapon anti-missile decision-makingoptimization based on collaboration[J], Control and Decision, 2007, 22 (3) : 299303

[2] Liang Bo, Duan Ran.Fire distribution model based on feasible direction algorithm $[\mathrm{J}]$, Command Information System and Technology, 2013,4 (2) :30-32

[3] Sarit Kraus.Negotiation and cooperation in mulfi-ageat environments.Artificial Intelligence. 1997 : 79-97

[4] HUANG Haixin, WANG Ding wei.English auction dynamic model based on fuzzy game[J], Information and Control,2012,41(4):509-513

[5] Shao Qiu feng, Ma ya long, hu jin chuan.Applied research for fuzzy composite operators in operational alternatives integrated evaluation[J],Journal of Academy of Armored Force Engineering, 2004, 18 (12) : 41-43

[6] MA Liang, QING Zuo-sheng, ZHANG Lin.Formation comprehensive cooperative air defense multi-stage decision optimization modeling[J], Tactical Missile Technology, 2013,9 (5) :25-28

[7] LIU Wei dong, JIANG Qing shan, LI Yong.Fire distribution of the network centric ship-to-air missile based on earlier damage[J],Ship Science And Technology, 2011,33 (2) :98-101 
[8] CHEN Guo sheng, JIA $\mathrm{Zi}$ ying.Research on coordinated air defense firepower distribution model for warships $[\mathrm{J}]$, Command ControI\& Simulation, 2011,33 (12) :13-15

[9] XU Z S. Multiple-attribute group decision making with different formats of preference information on attributes [J]. IEEE Trans on System, Man, and Cybernetics-Part B: Cybernetics, 2007, 37 (6) : 1500-1511.

[10] A.Hadi-Vencheh, M.Allame. On the relation between a fuzzy number and its centroid [J].Comput. Math. Appl, 2010, 59: 3578-3582

[11] Lee Z J, Su S F, Lee C Y. Efficiently solving general weapontarget assignment problem by genetic algorithms with greedy
eugenics[J].IEEE Transactions on Systems, Man and CyberneticsPartB, 2003, 33(1) : 113-121.

[12] Abdollah, Mahdi. Seclusion-Factor Method to solve fuzzymultiple criteria decision-making problems [J].IEEE Trans on Fuzzy Systems, 2011, 19 (2): 201-209.

[13] Beynon M J, Bruce Curry, Peter Morgan. The Dempster-Shafer theory of evidence: An alternative approach to multi-criteria decision modeling[J]. Omega, 2000, 28(1):37-50.

[14] Beynon M J. DS/AHP method: A mathematical analysis,including an understanding of uncertainty[J]. European $\mathrm{J}$ of Operational Research, 2002, 140(1): 148-164. 